\title{
Temporal variation of shear-wave splitting parameters before and after the 2008 Movri Mountain earthquake in northwest Peloponnese (Greece)
} \author{
Athanasios Lois ${ }^{1}$, G-Akis Tselentis ${ }^{1}$ \\ ${ }^{1}$ University of Patras, Seismological Laboratory, Patras, Greece \\ ${ }^{2}$ National Central University, Department of Earth Sciences, Jhongli, Taiwan
}

Dimitrios Giannopoulos ${ }^{1}$, Efthimios Sokos ${ }^{1,}$, Konstantinos I. Konstantinou ${ }^{2}$,

\author{
Article history \\ Received February 23, 2012; accepted June 30, 2012. \\ Subject classification: \\ Earthquake faults: properties and evolution, Tomography and anisotropy, Waves and wave analysis, Stress, Tectonics.
}

\begin{abstract}
On June 8, 2008, at 12:25 GMT, a $M_{W} 6.4$ earthquake, the Movri Mountain earthquake, occurred in the area of northwest Peloponnese, western Greece. The epicenter was located in the municipality of Movri, $35 \mathrm{~km}$ southwest of Patras. For this study, a crustal anisotropy analysis was performed in the epicentral area of the Movri Mountain earthquake. Specifically, the shear-wave splitting phenomenon and its temporal evolution in relation to the Movri Mountain earthquake was studied, using the cross-correlation method. The data analysis revealed the presence of shear-wave splitting in the study area. Both before and after the Movri Mountain earthquake, the polarization directions of the fast component of the shear waves followed a general NNW-SSE direction. The observed mean fast polarization direction was not consistent with the regional stress field, which showed a general E-W direction of the maximum horizontal compressive stress. The differences between the estimated fast polarization directions and the properties of the regional stress field suggest the presence of a local stress field in the area around the fault. An increase in time delays was observed soon after the Movri Mountain earthquake. The average value of the delay times before the earthquake was ca. $18 \pm 2.6 \mathrm{~ms}$, while after the earthquake this was ca. $40 \pm 4.6 \mathrm{~ms}$. This increase in the time delay indicates changes in the crustal properties, which were possibly caused by variations in the preexisting micro-crack system characteristics related to the Movri Mountain earthquake, and the possible involvement of over-pressured fluids.
\end{abstract}

\section{Introduction}

Shear-wave splitting is a phenomenon in which shearwaves are separated into two components with different polarization directions and propagation velocities. This can occur during $\mathrm{S}$-wave propagation through an anisotropic medium [Crampin and Chastin 2003, Crampin and Peacock 2005]. The two splitting parameters that can be measured through shear-wave data processing are the polarization direction $\varphi$ of the fast component of the shear waves, and the time delay $d t$ between the two components. Various models have been proposed to interpret the observed seismic anisotropy in the crust. The most widely accepted physical model, which is known as the extensive dilatancy anisotropy model [Crampin 1978, 1993, Crampin et al. 1984b], explains the principal cause of the shear-wave splitting phenomenon as S-wave propagation through stress-aligned, fluid-saturated micro-cracks with an orientation parallel/ sub-parallel to the direction of maximum horizontal compression. This model has since been modified, and led to the anisotropic poro-elasticity model [Crampin and Zatsepin 1997, Zatsepin and Crampin 1997], which explains the way in which such microcracks evolve in response to changing conditions in permeable rock. Several studies on local earthquakes worldwide have revealed shear-wave splitting in various geological settings that indicate anisotropic media [Kaneshima 1990, Crampin and Lovell 1991, Gao et al. 1998, Liu et al. 2008].

Changes in the parameters of the shear-wave splitting phenomenon have been observed worldwide in relation to earthquakes that have indicated changes in the anisotropic characteristics of the medium and the stress field [Gao and Crampin 2004, Crampin and Peacock 2008, Crampin and Gao 2012]. These variations in the shear-wave splitting parameters are complicated and have often been the subject of debate. Specifically, variations in shear-wave splitting time delays before large earthquakes have given rise to discussion [Crampin and Peacock 2008]. For instance, Liu et al. [2004] analyzed shear-wave splitting of foreshocks and aftershocks of the September 20, 1999, $\mathrm{M}_{\mathrm{W}}$ 7.6 Chi-Chi earthquake in Taiwan. No evidence was found for temporal changes in time delays over the periods before and after the mainshock. The authors suggested that the behavior in the dataset was affected by spatial variations of seismic anisotropy rather than by temporal variations. On the other hand, in commenting on a previous study, Crampin and Gao [2005] claimed that stress fluctuates during aftershock sequences 


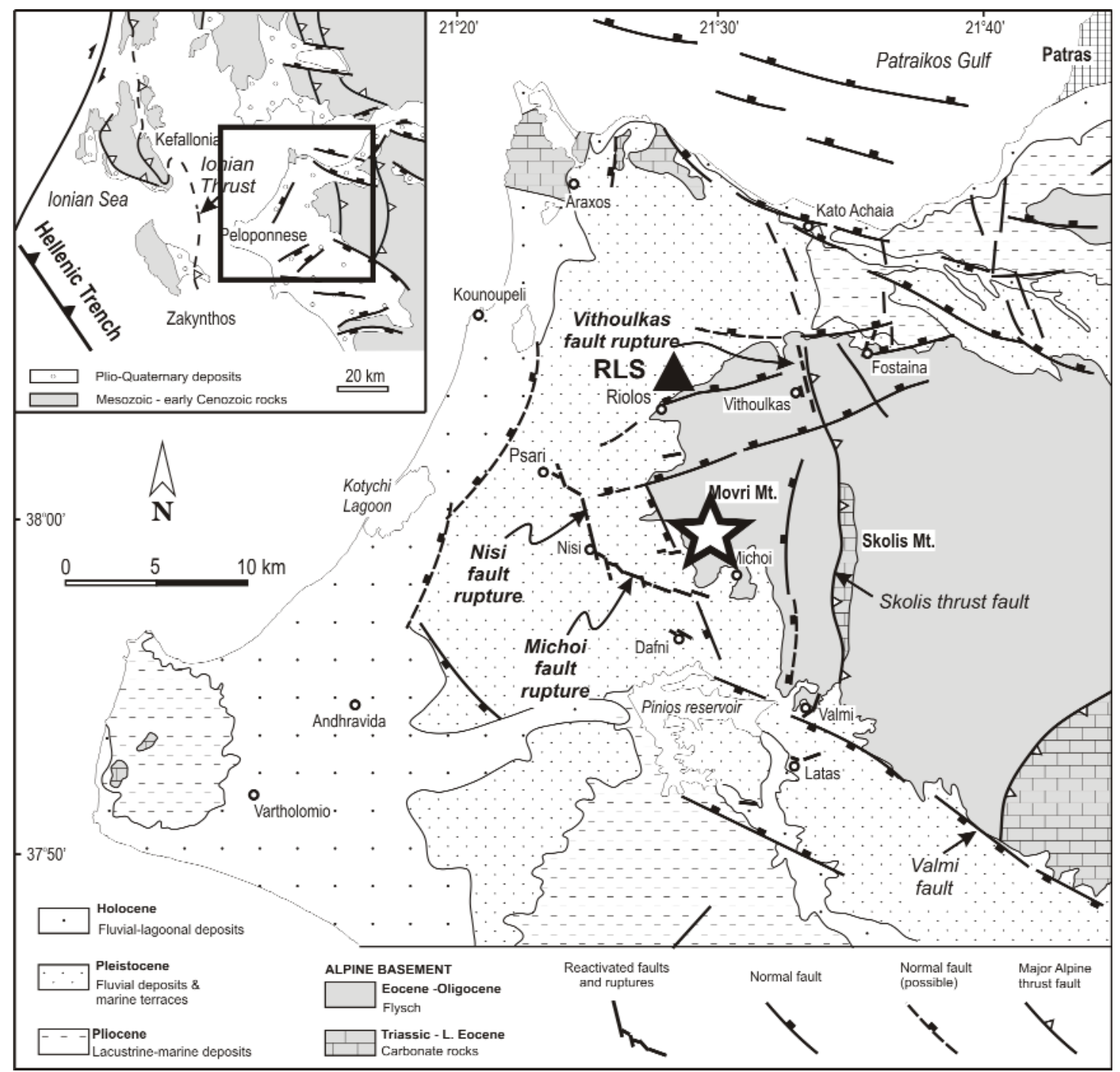

Figure 1. Geological map of northwest Peloponnese showing the active faults, the Movri Mountain earthquake epicenter (star), the Riolos (RLS) station (triangle), and the reactivated faults during the 2008 Movri Mountain earthquake, according to Koukouvelas et al. [2009]. Figure modified from Koukouvelas et al. [2009].

and systematic changes in time delays are not expected and have been observed. However, according to Crampin and Gao [2005], temporal variations of time delays were measured by Liu et al. [2004] before the Chi-Chi earthquake. These variations showed the same characteristic behavior, with comparable magnitude/ time-delay duration similarities as in other studies [e.g., Crampin and Gao [2005]. Liu et al. [2005] maintained their assessment that the results did not show systematic temporal evolution of anisotropy parameters that can be used to forecast impending large earthquakes.

In another case, Aster et al. [1990] measured time delays on the same seismograms from the Anza Seismic Network that Peacock et al. [1988] and Crampin et al. [1990] used to show systematic temporal changes before the 1986 M6 North Palm Springs earthquake in Southern California, USA. These authors showed that there were no temporal changes, using automatic techniques to measure time delays. Crampin et al. [1991] argued that some of the automatic time-delay measurements of Aster et al. [1990] were in error by a factor of up to $3(200 \%)$. They claimed that the inadequacy of all of the automatic measurements invalidated the conclusions of Aster et al. [1990], and the estimates of the time delays between the split shear waves were not reliable. Other cases in the literature that have provided observations of changes in splitting parameters related to earthquakes have been debated, and those under considerable discussion are Seher and Main [2004], Peng and Ben-Zion [2005], and Munson et al. [1995].

The tectonic and geological setting of western Greece is characterized by complex structures. The tectonic framework is dominated by the large dextral strike-slip fault off the coast of Kefallonia Island, where the change between continent-continent collision in the north and ocean-continent subduction in the south occurs [Underhill 1989, Sachpazi et al. 2000] (Figure 1). During the Eocene, northwestern Peloponnese was affected by the Alpine collision, which led to the formation of the Hellenic mountain range [Doutsos et al. 1993]. Mesozoic and Early Cenozoic carbonate rock propagated upwards and westwards along N-S-striking and E-dip- 
ping thrust faults [Xypolias and Doutsos 2000]. From the early Pliocene to the present, an extensional stress field has progressively prevailed in the previous compressional tectonic regime in northwestern Peloponnese [Doutsos and Kokkalas 2001].

The Movri Mountain earthquake occurred on June 8 , 2008, at 15:25 local time (12:25 GMT) in the area of northwest Peloponnese, western Greece. The main shock was accurately located by Konstantinou et al. [2009b] at a hypocentral depth of $18 \mathrm{~km}$, using a shrinking grid-search relocation algorithm. Several studies have been performed to investigate the aftershock distribution and the rupture process of this event [Ganas et al. 2009, Gallovič et al. 2009, Konstantinou et al. 2009b, Papadopoulos et al. 2010, Feng et al. 2010]. Various organizations have provided moment tensor solutions (e.g., Institute of Geodynamics of the National Observatory of Athens, Harvard University, United States Geological Survey, Aristotle University of Thessaloniki), which have indicated a nearly vertical dextral strike-slip fault striking NE-SW. The event was reported as an earthquake with a mean moment magnitude, $\mathrm{M}_{\mathrm{W}}$, of 6.4 , which is the largest instrumentally recorded event in this area to date [Konstantinou et al. 2009b].

The seismogenic fault of the Movri Mountain earthquake had no direct surface expression, and none of the major surface-fault ruptures in the area fit with a NNE-trending fault at depth [Koukouvelas et al. 2009]. Konstantinou et al. [2011] suggested that the presence of over-pressured fluids of deep origin might have been responsible for the elevated fluid pressure levels near the hypocenter that led to the reactivation of the unknown fault that generated this event.

In this study, we present evidence for shear-wave splitting processes in the epicentral area of the Movri Mountain earthquake. Specifically, we have detected variations in splitting parameters in relation to the Movri Mountain earthquake. We discuss the measured splitting parameters and their variations in comparison with the regional stress field, and also with the Movri Mountain earthquake.

\section{Data}

For the purpose of this study, three-component recordings from stations in continuous operation during the periods before and after the Movri Mountain earthquake were needed. The only station in the study area that satisfied this criterion was Riolos station (RLS). No other seismological station around the epicenter was equipped with a three-component seismometer and was operating continuously in the studied time periods. This station is part of the seismological network of the Institute of Geodynamics, National Observatory of Athens (GI-NOA) and the Hellenic Unified Seismological Network (HUSN). It is equipped with a threecomponent, broadband sensor and it is located in Riolos village, about $13 \mathrm{~km}$ from the epicenter of the Movri Mountain earthquake, in northwestern Peloponnese (Figure 1).
The seismicity studied here consisted of background earthquakes near to the seismogenic fault and aftershocks of the $\mathrm{M}_{\mathrm{W}}$ 6.4 Movri Mountain earthquake. The dataset for the period before the Movri Mountain earthquake was recorded from June 4, 2003, until September 27, 2007, and for the period after the occurrence of the earthquake, from June 10, 2008, until July 13, 2008. The local magnitudes varied between 1.3 and 3.5. We used records from 12 events for the first period and records from 207 events for the second period. For the first period of interest, we used the event locations provided by GI-NOA, using recordings from GINOA and the Patras Seismological Laboratory Network (http:// seismo.geology.upatras.gr/). The location errors in the horizontal and vertical directions associated with event locations by GI-NOA did not exceed $2 \mathrm{~km}$. For the second period of interest, we used the event locations determined by Konstantinou et al. [2009b]. There were fewer seismic events available before the Movri Mountain earthquake because the seismicity in the area was low. This reason mostly explains the small number of events available for the first period.

An important data-selection criterion in shear-wave splitting analysis is related to the incidence angle of the shear waves. S-waves have such severe interactions with the free surface that almost all of the similarities with the incoming waveform are irretrievably lost when they reach the surface at incidence angles greater than a critical value. The critical value is given by $\sin ^{-1}(\mathrm{Vs} / \mathrm{Vp})$, where $\mathrm{Vs}$ and $\mathrm{Vp}$ are the $\mathrm{S}$-wave and $\mathrm{P}$-wave velocities at the source [Booth and Crampin 1985]. Using the local one-dimensional velocity model by Haslinger et al. [1999], the critical angle for our study was estimated at $34.5^{\circ}$. Records of the events within the shear-wave window of the RLS station were searched, to obtain clean and impulsive S-phases on the horizontal components.

\section{Methods}

For the estimation of the splitting parameters in our dataset, we applied the cross-correlation method [Ando et al. 1983], as described by Konstantinou et al. [2009a]. Before applying this method, we manually picked the P-wave and S-wave arrival times of our waveform dataset. The seismograms were interpolated to 200 samples s $^{-1}$, integrated to displacement, and then band-pass filtered with corner frequencies of $1 \mathrm{~Hz}$ and $10 \mathrm{~Hz}$. The measurement window for each waveform was defined in the following way, as described by Konstantinou et al. [2009a]: the start of the window was fixed as $0.05 \mathrm{~s}$ before the $\mathrm{S}$-wave arrival, while the endpoint was adjusted each time until the value of the crosscorrelation coefficient $C$ between the fast and slow components reached a maximum. The reasoning behind this choice of window measurement was because the suitable endpoint might actually vary with different waveform characteristics. According to cross-correlation methods, both horizontal seismograms are rotated in the horizontal plane at $1^{\circ}$ increments 
RLS $200861020: 41$
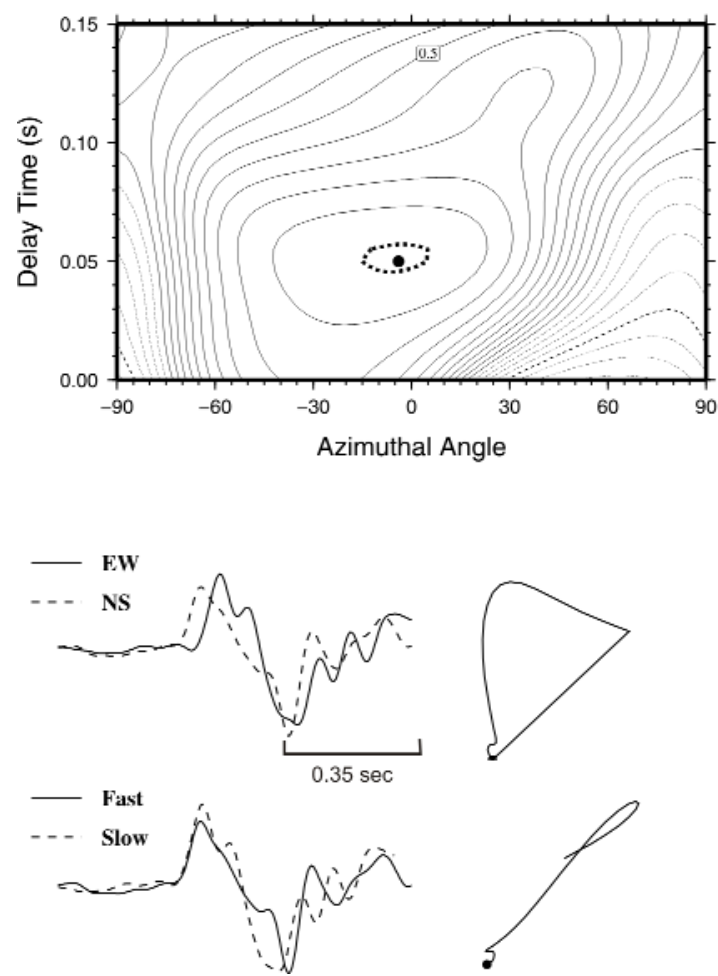

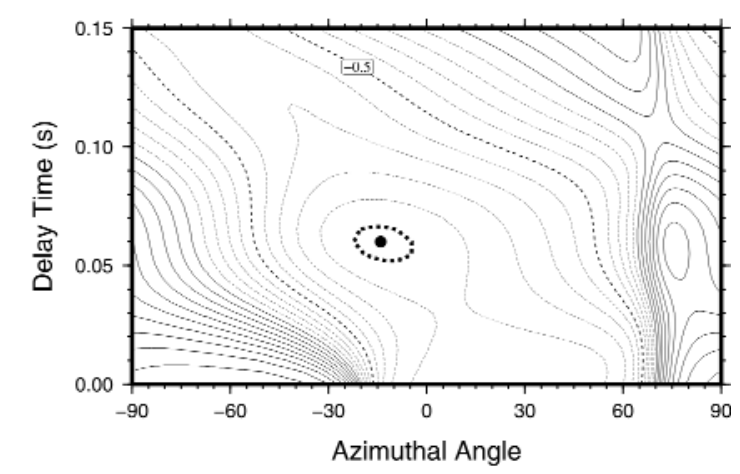

RLS $200861913: 40$

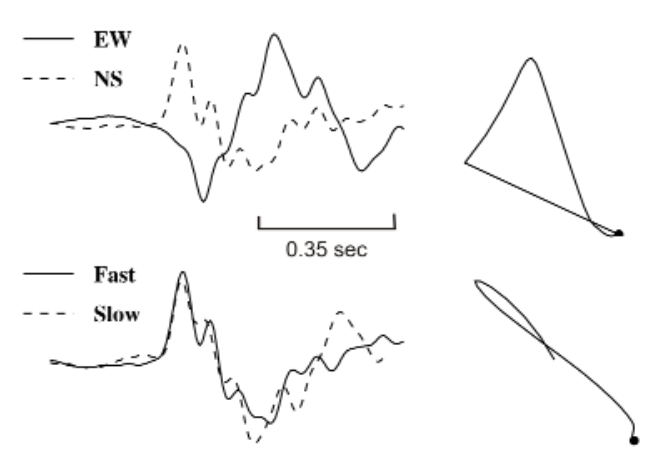

Figure 2. Valid splitting measurements of the S-waves recorded at the RLS station for two events that occurred in June 10, 2008, and June 19, 2008. Upper panel: Contour diagrams of the cross-correlation coefficients in the $(\varphi, d t)$ space. The preferred solutions $(\varphi, d t)$ corresponding to the maximum absolute values (dot) are shown within the $95 \%$ confidence region (dotted line). Lower panel: Superposition of E-W and N-S components (upper traces), and the corrected fast and slow components (lower traces). Particle motions are shown to the right of each sub-panel.

of azimuth $(\alpha)$ from $-90^{\circ}$ to $90^{\circ}$. Then, for each azimuth, the cross-correlation coefficient $C$ is calculated between the two orthogonal seismograms, for a range of time delays $(\tau)$ in a selected time window. When the absolute value of $C$ reaches a maximum, the corresponding values of azimuth $(\alpha)$ and time $(\tau)$ are chosen as the fast polarization direction and the time delay between the separated shear waves, respectively. The measurement uncertainty was estimated using a t-test at a $95 \%$ confidence level on the values of $C$, as described by Kuo et al. [1994]. Following Liu et al. [2008] and Konstantinou et al. [2009a], we accepted the splitting measurements as valid that conformed to the following criteria: (a) the $C$ value was $>0.80$; (b) the signal-to-noise ratio was $>3$; (c) the change in the measured $d t$ was $<0.02 \mathrm{~s}$ when the window size was varied by $\pm 0.02 \mathrm{~s}$; and (d) the change in the measured $\varphi$ was $<10^{\circ}$ when the window size was varied by \pm 0.02 s. With the application of these criteria, 132 events were selected, and the splitting parameters for both of the periods were computed (before and after the Movri Mountain earthquake). Two examples of the valid splitting measurements are shown in Figure 2.

\section{Results}

After the analysis of the S-waves, we obtained valid data $(\varphi, d t)$ from 10 seismic events for the period before the Movri Mountain earthquake (Figure 3). The raw delay times varied between $5 \mathrm{~ms}$ and $50 \mathrm{~ms}$, with a mean of $18 \pm 2.8 \mathrm{~ms}$ (median, $10 \mathrm{~ms}$ ), while the polarization directions of the fast components varied between $108^{\circ}$ and $226^{\circ}$, with a mean direction of $166^{\circ} \pm 13^{\circ}$. The time delays were normalized according to the hypocentral distances, and showed a mean of $4 \pm 0.6 \mathrm{~ms} / \mathrm{km}$. The fast shear-wave polarization directions are presented in Figure 5 as rose diagrams. For the period after the Movri Mountain earthquake, we obtained valid results $(\varphi, d t)$ from 122 seismic events (Figure 4). The raw delay times varied between $5 \mathrm{~ms}$ and $115 \mathrm{~ms}$, with a mean of 40 $\pm 4.6 \mathrm{~ms}$ (median, $43 \mathrm{~ms}$ ), while the polarization directions of the fast components varied between $106^{\circ}$ and $231^{\circ}$, with a mean direction of $161^{\circ} \pm 8^{\circ}$. The time delays were again normalized according to the hypocentral distances, and showed a mean of $11 \pm 1.3 \mathrm{~ms} / \mathrm{km}$ for this period. The fast shear-wave polarization directions are presented in Figure 5 as rose diagrams.

In the following paragraphs, we discuss the measured splitting parameters and their variations before and after the Movri Mountain earthquake.

\subsection{Polarization directions}

Comparison of the mean polarization directions that were estimated for both periods, and also taking into account the measurement errors, the fast polarization directions followed a general NNW-SSE direction during both 

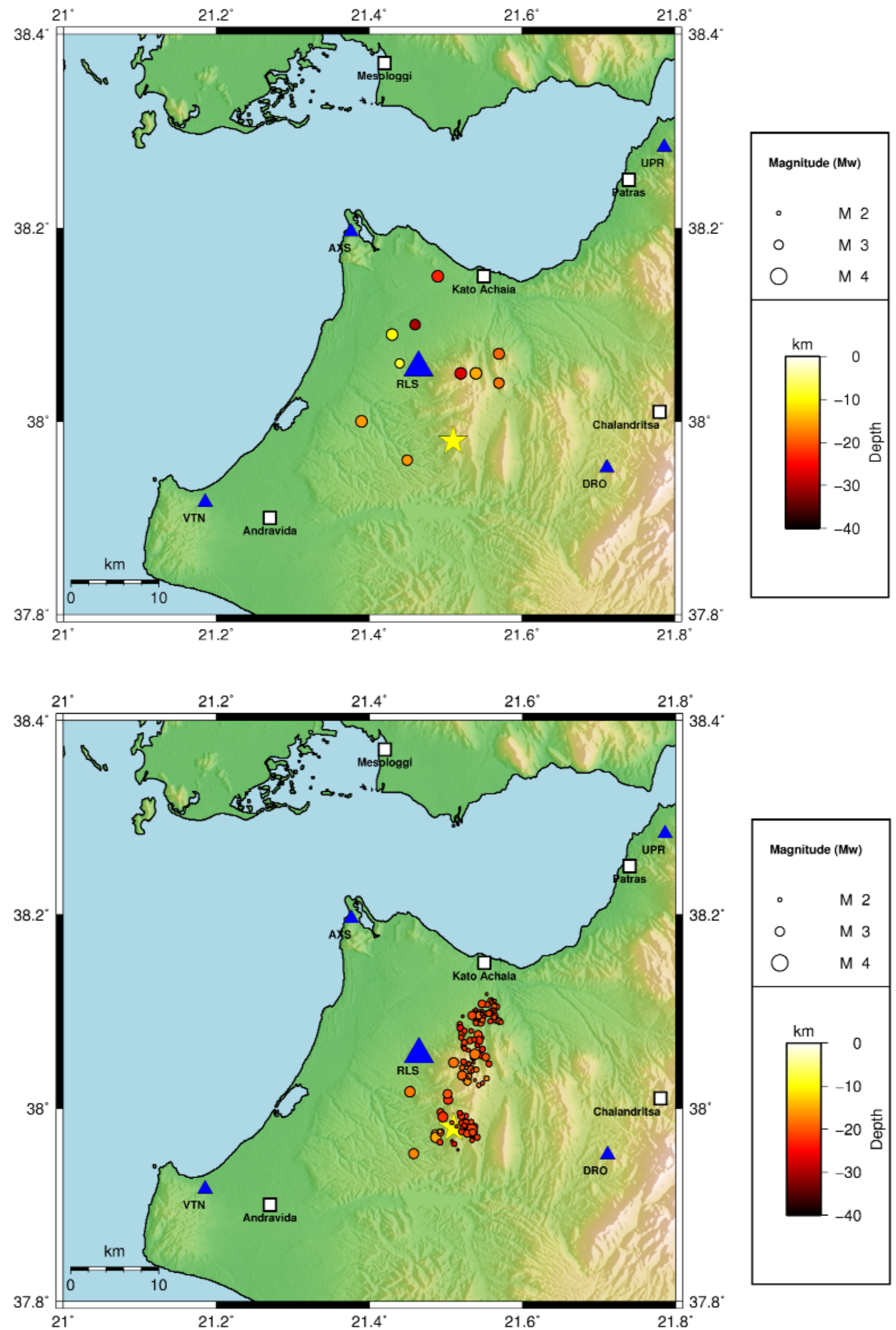

Figure 3 (top). Map of northwestern Peloponnese, showing the events from which the valid splitting results were obtained for the period before the Movri Mountain earthquake. The RLS station (large triangle), some of the HUSN seismic stations (small triangles), the Movri Mountain earthquake epicenter (star), and the major cities (squares) are shown. The colored circles represent epicenters. The depths of the events are color coded according to the color scale (right). The diameters of the circles are proportional to the magnitudes.

Figure 4 (bottom). Map of northwestern Peloponnesus, showing the events from which the valid splitting results were obtained for the period after the Movri Mountain earthquake. The RLS station (triangle), some of the HUSN seismic stations (small triangles), the Movri Mountain earthquake epicenter (star), and the major cities (squares) are shown. The colored circles represent epicenters. The depths of the events are color coded according to the color scale (right). The diameters of the circles are proportional to the magnitudes. 



Figure 5. Rose diagrams of the fast shear-wave polarization directions before (a) and after (b) the Movri Mountain earthquake. The arrows represent the mean fast shear-wave polarization directions.

periods. The Movri Mountain earthquake had little or no influence on these polarization directions, and this conclusion was confirmed by the statistical test that we applied, relative to the directional data [Trauth 2010]. In particular, the test statistic that was used for the testing of the similarity between the two mean directions (before and after the Movri Mountain earthquake) was a modified F-statistic for the directional data. The application to our data of the specific test with a level of significance of $5 \%$ resulted in a test value of $\boldsymbol{F}=0.85$, and a critical value of $\boldsymbol{F}_{c r}=1.44$. According to theory (see Appendix A), as $F<F_{c r}$, we can conclude that there is no statistical evidence that supports the rejection of the null hypothesis, and therefore these two samples of data have been drawn from populations with the same mean direction.

\subsection{Delay times}

Delay times are very sensitive to small changes in the geometry of micro-fractures / micro-cracks in the crust. Particularly in cases of earthquakes, there are noticeable variations in time delays that can be ascribed to stress and rock-mass strain changes [Crampin and Lovell 1991]. The delay times estimated for the period before the Movri Mountain earthquake had a mean of $18 \pm 2.8 \mathrm{~ms}$ (median, $10 \mathrm{~ms}$ ), while after the Movri Mountain earthquake, there was an increase to a mean of $40 \pm 4.6 \mathrm{~ms}$ (median, $43 \mathrm{~ms}$ ). This change was also validated following a non-parametric hypothesistesting framework. Specifically, a two-sample KolmogorovSmirnov (KS) test was applied to our data [Gibbons 1971], with a level of significance of $5 \%$. The test value of $q$ and the critical value derived from the Kolmogorov distribution, $\boldsymbol{K}_{\boldsymbol{\alpha}}$, were 0.41 and 0.05 , respectively. Following theory (see Appendix B), as $q>K_{\alpha}$, we can conclude that the null hypothesis has to be rejected; i.e., the two datasets were not drawn from the same distribution.

\section{Interpretation and discussion}

The Movri Mountain earthquake occurred on a pre-existing strike-slip fault that was probably inherited from past tectonic processes, and it affected the area of northwestern Peloponnese. The strike of the fault was $210^{\circ}$, as determined by seismological means [Konstantinou et al. 2009b].

Konstantinou et al. [2011] performed a stress inversion of all of the available focal mechanisms in this area, and they estimated that the principal compressive stress axis of the regional stress field has an azimuth of ca. $273^{\circ}$, which forms an angle of ca. $63^{\circ}$ with the strike of the fault. The angle between the strike of the fault and the $\sigma_{1}$ of the regional stress field implies that the fault was severely misoriented compared to the regional prevailing stress field. This means that the Movri Mountain earthquake occurred within an unfavorable stress regime. According to Sibson [1990], for seismogenic fault reactivation to occur, a favorable orientation between the strike of the fault and $\sigma_{1}$ is needed. Konstantinou et al. [2011] suggested that the presence of fluid might have facilitated the reactivation of the fault, to cause the Movri Mountain event. Fluid might have allowed the fault to slip, by rotation of the principal stress axis locally around the fault to more favorable angles. Fluids are sourced from the lower crust or upper mantle, and possibly the relatively permeable and fractured fault zone provided a passage [Konstantinou et al. 2011]. To confirm that there were fluids in the area, Konstantinou et al. [2011] made use of a database of helium isotope measurements around Greece and the surrounding areas that was compiled by Pik and Marty [2009]. One such measurement taken at a location of $\left(37.733^{\circ} \mathrm{N}\right.$, $21.383^{\circ} \mathrm{E}$ ), which was about $20 \mathrm{~km}$ from the Movri Mountain earthquake epicenter, showed a significant percentage (ca. 7\%) of mantle helium. Furthermore, tomographic imaging of $P_{n}$ velocities performed by Al-Lazki et al. [2004] indicated abnormally low $\mathrm{P}_{\mathrm{n}}$ velocities beneath northwest Peloponnese. 

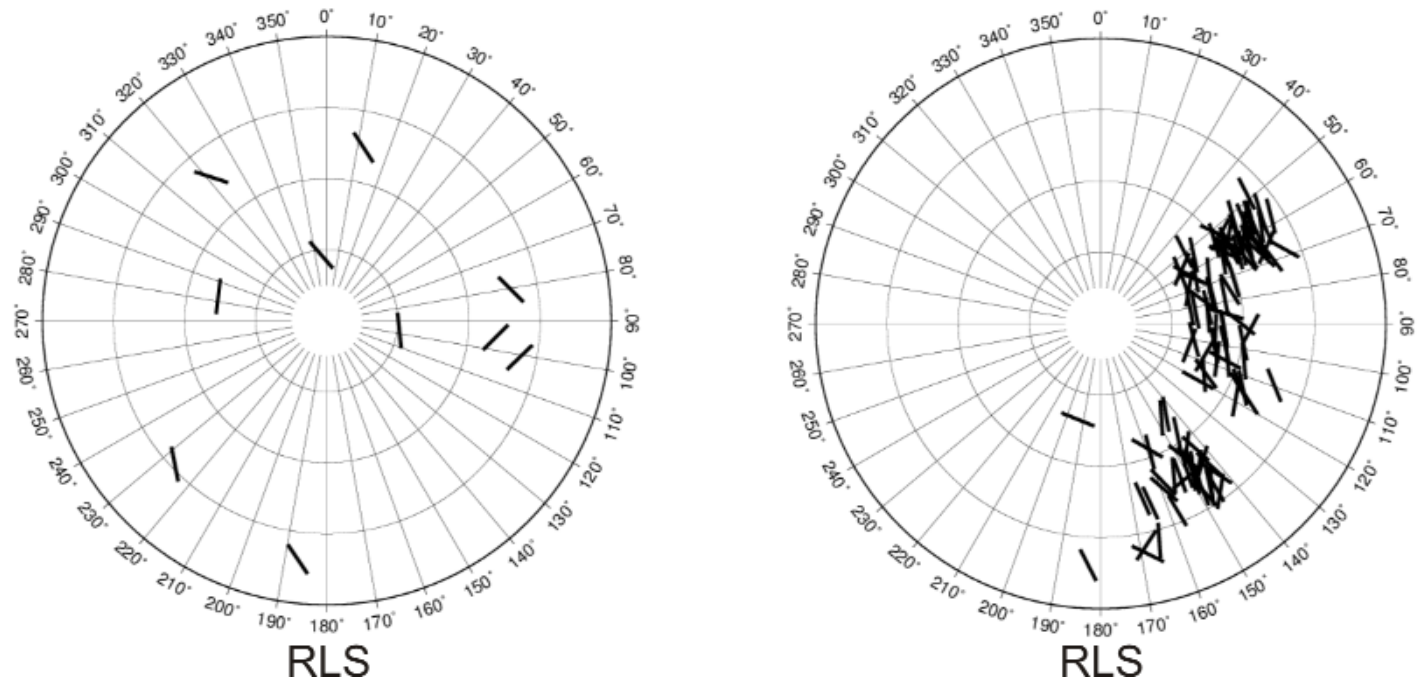

Figure 6. Equal area projections of the polarization directions measured at the RLS station for the periods before (left) and after (right) the Movri Mountain earthquake. The radius of the plots is scaled to an incidence angle of $40^{\circ}$.

\begin{tabular}{|c|c|c|c|c|c|c|c|c|}
\hline Date & Origin time & Longitude & Latitude & $\begin{array}{l}\text { Distance } \\
\quad(\mathbf{k m})\end{array}$ & $\begin{array}{l}\text { Hypocentral } \\
\text { depth }(\mathrm{km})\end{array}$ & $\begin{array}{l}\text { Delay time } \\
\quad(\mathrm{ms})\end{array}$ & $\begin{array}{l}\text { Normalized delay } \\
\text { time }(\mathrm{ms} / \mathrm{km})\end{array}$ & $\begin{array}{l}\text { Fast polarization } \\
\text { direction }\left({ }^{\circ}\right)\end{array}$ \\
\hline $2006 / 10 / 24$ & $18: 47: 25$ & 37.960 & 21.450 & \multirow{2}{*}{1.05} & 16 & 10 & 3.02 & 146 \\
\hline $2008 / 07 / 11$ & $14: 55: 31$ & 37.953 & 21.458 & & 17 & 55 & 15.71 & 153 \\
\hline $2005 / 07 / 18$ & 01:46:39 & 38.040 & 21.570 & \multirow{2}{*}{2.63} & 18 & 5 & 1.01 & 226 \\
\hline $2008 / 06 / 27$ & $09: 52: 24$ & 38.040 & 21.540 & & 18 & 60 & 18.29 & 175 \\
\hline $2005 / 07 / 18$ & 01:46:39 & 38.040 & 21.570 & \multirow{2}{*}{3.78} & 18 & 5 & 1.01 & 226 \\
\hline $2008 / 07 / 12$ & $00: 38: 13$ & 38.042 & 21.527 & & 17 & 30 & 9.77 & 175 \\
\hline $2007 / 05 / 27$ & $20: 14: 31$ & 38.070 & 21.570 & \multirow{2}{*}{4.25} & 19 & 5 & 0.80 & 135 \\
\hline $2008 / 06 / 27$ & $09: 52: 24$ & 38.040 & 21.540 & & 18 & 60 & 18.29 & 175 \\
\hline $2005 / 07 / 18$ & 01:46:39 & 38.040 & 21.570 & \multirow{2}{*}{4.31} & 18 & 5 & 1.01 & 226 \\
\hline $2008 / 06 / 14$ & 01:00:22 & 38.042 & 21.521 & & 19 & 30 & 8.98 & 210 \\
\hline $2007 / 05 / 27$ & $20: 14: 31$ & 38.070 & 21.570 & \multirow{2}{*}{4.89} & 19 & 5 & 0.80 & 135 \\
\hline $2008 / 07 / 12$ & $00: 38: 13$ & 38.042 & 21.527 & & 17 & 30 & 9.77 & 175 \\
\hline
\end{tabular}

Table 1. Location and splitting parameters for the selected pairs of events with nearby locations, before and after the Movri Mountain earthquake (June 8 , 2008). Time-delays are normalized to a $1-\mathrm{km}$ path lengths.

These low $\mathrm{P}_{\mathrm{n}}$ velocities might represent molten areas in the upper mantle, which can be considered as possible sources of degassing fluids.

According to Konstantinou et al. [2011], another possible explanation of this reactivation is that the fault gouge consisted of weak material, with friction coefficients much less than 0.6 , which would extend the domain of favorable orientation without making necessary the presence of overpressured fluids. However, most fault gouge minerals that show weak behavior at shallow depths have been shown to be significantly stronger at greater depths. Therefore, the great depth of the Movri Mountain earthquake suggests that the misorientation of the fault cannot be explained by the presence of weak materials. 
Fast polarization directions are usually parallel or subparallel to the present-day direction of the maximum compressive stress throughout at least the uppermost $20 \mathrm{~km}$ of the crust [Crampin and Lovell 1991]. The mean fast polarization orientation obtained using the complete dataset of the present study was $164^{\circ} \pm 10^{\circ}$, and thus we can claim that the direction of the maximum horizontal compressive stress in the study area was almost parallel to this. Consequently, this indicates a local stress field in the vicinity of the fault that had different characteristics from those of the prevailing regional stress field. More specifically, the local principal stress axis was measured as approximately orthogonal (ca. $100^{\circ}$ ) to the regional compressive stress. This is possibly a case of ca. $90^{\circ}$-flip above earthquakes in the vicinity of a major strikeslip fault, as has been reported in several studies that have indicated a key role for over-pressured fluids in the splitting parameters and in earthquake source mechanisms [Crampin et al. 2002, Liu et al. 1997, Peacock et al. 1988]. From the comparison of the strike of the fault $\left(210^{\circ}\right)$ and the mean fast polarization direction $\left(164^{\circ} \pm 10^{\circ}\right)$, we infer that the angle between the strike of the fault and the rotated principal local stress axis was $46^{\circ} \pm 10^{\circ}$. It appears that the local $\sigma_{1}$ was rotated towards lower angles to the fault compared to the regional $\sigma_{1}$. This supports the suggestion of Konstantinou et al. [2011], according to which for the Movri Mountain earthquake to occur, $\sigma_{1}$ had to form locally smaller and more favorable angles in relation to the strike of the fault. Our data characterize a specific area that was the part of the crust within the shear-wave window of the RLS station, and not the broader epicentral area. For this reason, we consider our findings as an indication of local rotated fields that acted around the seismogenic fault.

In terms of the time-delay variations, we note that the spatial distribution of the events before and after the Movri Mountain earthquake were different. Figure 6 presents the fast polarization directions on equal area projections for the RLS station, which shows the different azimuthal distributions of the shear-wave sources of both of the periods. This difference in ray paths might have biased the time-delay observations. To study such an effect, it would be relatively effective if we could compare any doublets or multiplets. As this was not feasible for our dataset, we selected earthquakes from each period that had, as far as possible, nearby locations. The location parameters and the measured time delays (raw and normalized) of the closely located pairs of events are listed in Table 1. Figure 8 shows the waveforms of the two first pairs from Table 1. With this approach, we managed to compare the splitting parameters, and especially the time delays, for similar ray paths. Considering that the majority of the events were located at similar depths (see Figure 7) and that the geological structure of this studied part of the crust shows the same lithostratigraphic units [Kamberis et al. 2005], the previous comparison becomes more credible. This analysis confirms the previously derived results that precluded any ray-path bias.

According to our data, we suggest that the shear-wave splitting in the epicentral area of Movri Mountain earthquake was most probably caused by fluid-saturated micro-


Figure 7. Raw and normalized time delays plotted versus the focal depth of all of the events used in this study, for both periods of interest. No systematic relations are seen between the time delays and the depth. The detected anisotropy is distributed above the depth of $15 \mathrm{~km}$. 



Figure 8. Three-component waveform plots of two pairs of closely located events, as listed in Table 1 . The waveforms were band-pass filtered between $1 \mathrm{~Hz}$ and $10 \mathrm{~Hz}$, and the event dates are indicated at the top.

cracks that were oriented parallel or sub-parallel to the maximum compressive stress axis of a local stress field in the vicinity of the fault. The earthquake caused a change in the deformation level of the crust and micro-crack system geometry (including the crack density and aspect ratio). The observed mean increase in the time delays on the one hand, and the maintenance of the same mean fast polarization direction after the Movri Mountain earthquake on the other hand, suggest that the cause of the observed variations in the splitting parameters was the possible migration of over-pressured fluids through the pre-fractured damage zone of the fault.

\section{Conclusions}

The shear-wave splitting analysis results presented in this study can be summarized as follows: (a) disagreement between the fast polarization directions and the orientation of the regional stress field; (b) fast polarization directions that did not change after the Movri Mountain earthquake; (c) time delays that increased soon after the Movri Mountain earthquake; and (d) these results might further support fluid involvement in the Movri Mountain earthquake.
These results provoke the need for further investigations, to study the disagreement between the polarization directions and the characteristics of the stress field of the broader area in more detail.

\section{Data and resources}

The waveform data recorded by RLS station were provided by the Institute of Geodynamics of National Observatory of Athens (www.gein.noa.gr/services/cat.html). The Figures were created using the Generic Mapping Tool software (http: / / www.soest.hawaii.edu / gmt/) [Wessel and Smith 1998]. Data analysis was performed using the Seismic Analysis Code software that was developed at Lawrence Livermore National Laboratory, CA, USA.

Acknowledgements. The authors would like to thank the Institute of Geodynamics of the National Observatory of Athens for providing the seismic records used in this study. K.I. Konstantinou would like to thank the National Science Council of Taiwan for financial support for this study. We are grateful to Associate Editor Francesca Bianco, Prof. Edoardo Del Pezzo, Prof. Stuart Crampin and an anonymous reviewer for their helpful comments and suggestions. 


\section{References}

Al-Lazki, A.I., E. Sandvol, D. Seber, M. Barazangi, N. Turkelli and R. Mohamad (2004). $\mathrm{P}_{\mathrm{n}}$ tomographic imaging of mantle lid velocity and anisotropy at the junction of the Arabian, Eurasian and African plates, Geophys. J. Int., 158, 1024-1040.

Ando, M., Y. Ishikawa and F. Yamazaki (1983). Shear wave polarization anisotropy in the upper mantle beneath Honshu, Japan, J. Geophys. Res., 88, 5850-5864.

Aster, R., P. Shearer and J. Berger (1990). Quantitative measurements of shear-wave polarizations at the Anza seismic network, southern California: implications for shear-wave splitting and earthquake prediction, J. Geophys. Res., 95, 12449-12473.

Booth, D.C., and S. Crampin (1985). Shear-wave polarizations on a curved wavefront at an isotropic free-surface, Geophys. J. R. Astron. Soc., 83, 31-45.

Crampin, S. (1978). Seismic-wave propagation through a cracked solid: Polarization as a possible dilatancy diagnostic, Geophys. J. R. Astron. Soc., 53, 467-496.

Crampin, S., J.R. Evans and B.K. Atkinson (1984b). Earthquake prediction: a new physical basis, Geophys. J. R. Astron. Soc., 76, 147-156.

Crampin, S., D.C. Booth, R. Evans, S. Peacock and J.B. Fletcher (1990). Changes in shear wave splitting at Anza near the time of the North Palm Springs Earthquake, J. Geophys. Res., 95, 11197-11212.

Crampin, S., and J.H. Lovell (1991). A decade of shear-wave splitting in the Earth's crust: what does it mean, what use can we make of it, and what should we do next?, Geophys. J. Int., 107, 387-407.

Crampin, S., D.C. Booth, R. Evans, S. Peacock and J.B. Fletcher (1991). Comment on "Quantitative measurements of shear wave polarizations at the Anza seismic network, Southern California: implications for shear wave splitting and earthquake prediction" by R.C. Aster, P.M. Shearer and J. Berger, J. Geophys. Res., 96, 6403-6414.

Crampin, S. (1993). Arguments for EDA, Can. J. Exp. Geophys., 29, 3-17.

Crampin, S., and S.V. Zatsepin (1997). Modelling the compliance of crustal rock-II. Response to temporal changes before earthquakes, Geophys. J. Int., 129, 495-506.

Crampin, S., T. Volti, S. Chastin, A. Gudmundsson and R. Stefánsson (2002). Indication of high pore-fluid pressures in a seismically-active fault zone, Geophys. J. Int., 151, F1-F5.

Crampin, S., and S. Chastin (2003). A review of shear wave splitting in the crack-critical crust, Geophys. J. Int, 155, 221-240.

Crampin, S., and Y. Gao (2005). Comment on "Systematic analysis of shear-wave splitting in the aftershock zone of the 1999 Chi-Chi, Taiwan, earthquake: shallow crustal anisotropy and lack of precursory changes", by Liu, Teng, Ben-Zion, Bull. Seismol. Soc. Am., 95, 354-360.
Crampin, S., and S. Peacock (2005). A review of shear-wave splitting in the compliant crack-critical anisotropic Earth Wave Motion, 41, 59-77.

Crampin, S., and S. Peacock (2008). A review of the current understanding of shear-wave splitting and common fallacies in interpretation, Wave Motion, 45, 675-722.

Crampin, S., and Y. Gao (2012). Plate-wide deformation before the Sumatra-Andaman Earthquake, J. Asian Earth Sci., 46, 61-69.

Doutsos, T., G. Pe-Piper, K. Boronkay and I. Koukouvelas (1993). Kinematics of the Central Hellenides, Tectonics, 12, 936-953.

Doutsos, T., and S. Kokkalas (2001). Stress and deformation patterns in the Aegean region, J. Struct. Geol., 23, 455472.

Feng, L., A.V. Newman, G.T. Farmer, P. Psimoulis and S.C. Stiros (2010). Energetic rupture, coseismic and post-seismic response of the $2008 \mathrm{M}_{\mathrm{W}}$ 6.4 Achaia-Elia earthquake in northwestern Peloponnese, Greece: an indicator of an immature transform fault zone, Geophys. J. Int., 183, 103110.

Gallovič, F., J. Zahradník, D. Křížova, V. Plicka, E. Sokos, A. Serpetsidaki and G-A. Tselentis (2009). From earthquake centroid to spatial-temporal rupture evolution: $\mathrm{M}_{\mathrm{W}} 6.3$ Movri Mountain earthquake, June 8, 2008, Greece, Geophys. Res. Lett., 36, L21310; doi:10.1029/2009GL040283.

Ganas, A., E. Serpelloni, G. Drakatos, M. Kolligri, I. Adamis, Ch. Tsimi and E. Batsi (2009). The $\mathrm{M}_{\mathrm{W}}$ 6.4 SW-Achaia (western Greece) earthquake of 8 June 2008: seismological, field, GPS observations, and stress modeling, J. Earthqu. Engin., 13, 1101-1124.

Gao, Y., P.-D. Wang, S.-H. Zheng, M. Wang, Y.-T Chen and H.L. Zhou (1998). Temporal changes in shear-wave splitting at an isolated swarm of small earthquakes in 1992 near Dongfang, Hainan Island, southern China, Geophys. J. Int., 135, 102-112.

Gao, Y., and S. Crampin (2004). Observations of stress relaxation before earthquakes, Geophys. J. Int., 157, 578-582.

Gibbons, J.D. (1971): Nonparametric Statistical Inference, McGraw-Hill, New York.

Haslinger, F., E. Kissling, J. Ansorge, D. Hatzfeld, E. Papadimitriou, V. Karakostas, K. Makropoulos, H.-G. Kahle, and Y. Peter (1999). Three-dimensional crustal structure from local earthquake tomography around the Gulf of Arta (Ionian region, NW Greece), Tectonophysics, 304, 201-218.

Kamberis, E., A. Pavlopoulos, S. Tsaila-Monopoli, S. Sotiropoulos and C. Ioakim (2005). Deep-water sedimentation and paleogeography of foreland basins in the NW Peloponnese (Greece), Geologica Carpathica, 56, 503-515.

Kaneshima, S. (1990). Original of crustal anisotropy: Shear wave splitting studies in Japan, J. Geophys. Res., 95, 1112111133. 
Koukouvelas, I.K., S. Kokkalas and P. Xypolias (2009). Surface deformation during the $\mathrm{M}_{\mathrm{W}} 6.4$ (8 June 2008) Movri Mountain earthquake in the Peloponnese, and its implications for the seismotectonics of western Greece, Int. Geol. Rev., 52, 249-268.

Konstantinou, K.I., C.H. Lin, W.T. Liang and Y.C. Chan (2009a). Seismogenic stress field beneath the Tatun Volcano Group, northern Taiwan, J. Volcanol. Geotherm. Res., 187, 261-271.

Konstantinou, K.I., N.S. Melis, S.-J. Lee, C.P. Evangelidis and K. Boukouras (2009b). Rupture process and aftershocks relocation of the 8 June $2008 \mathrm{M}_{\mathrm{W}} 6.4$ earthquake in northwest Peloponnese, western Greece, Bull. Seismol. Soc. Am., 99, 3374-3389.

Konstantinou, K.I., C.P. Evangelidis and N.S. Melis (2011). The 8 June $2008 \mathrm{M}_{\mathrm{W}} 6.4$ earthquake in northwest Peloponnese, western Greece: a case of fault reactivation in an overpressured lower crust?, Bull. Seismol. Soc. Am., $101,438-445$.

Kuo, B.Y., C.C. Chen and T.C. Shin (1994). Split S waveforms observed in northern Taiwan: implications for crustal anisotropy, Geophys. Res. Lett. 21, 1491-1494.

Liu, Y., S. Crampin and I. Main (1997). Shear-wave anisotropy: spatial and temporal variations in time delays at Parkfield, Central California, Geophys. J. Int., 130, 771785.

Liu, Y., T.-L. Teng and Y. Ben-Zion (2004). Systematic analysis of shear-wave splitting in the aftershock zone of the 1999 Chi-Chi, Taiwan, earthquake: shallow crustal anisotropy and lack of precursory changes, Bull. Seismol. Soc. Am., 94, 2330-2347.

Liu, Y., Y. Ben-Zion and T.-L. Teng (2005). Reply to "Comments on 'Systematic analysis of shear-wave splitting in the aftershock zone of the 1999 Chi-Chi, Taiwan, Earthquake: shallow crustal anisotropy and lack of precursory changes' by Y. Liu, T.-L. Teng, Y. Ben-Zion" by S. Crampin, Y. Gao, Bull. Seismol. Soc. Am., 95, 361-366.

Liu, Y., H. Zhang, C. Thurber and S. Roecker (2008). Shear wave anisotropy in the crust around the San Andreas fault near Parkfield: spatial and temporal analysis, Geophys. J. Int., 172, 957-970.

Munson, C.G., C.H. Thurber, Y. Li, and P.G. Okubo (1995). Crustal shear wave anisotropy in southern Hawaii: spatial and temporal analysis, J. Geophys. Res., 100, 2036720377.

Papadopoulos, G.A., V. Karastathis, C. Kontoes, M. Charalampakis, A. Fokaefs and I. Papoutsis (2010). Crustal deformation associated with east Mediterranean strike-slip earthquakes: the 8 June 2008 Movri (NW Peloponnese), Greece, earthquake (MW 6.4), Tectonophysics 492, 201212.

Peacock, S., S. Crampin, D.C. Booth and J.B. Fletcher (1988). Shear-wave splitting in the Anza seismic gap, southern
California: temporal variations as possible precursors, J. Geophys. Res., 93, 3339-3356.

Peng, Z., and Y. Ben-Zion (2005). Spatiotemporal variations of crustal anisotropy from similar events in aftershocks of the 1999 M 7.4 Izmit and M 7.1 Düzce, Turkey, earthquake sequences, Geophys. J. Int., 160, 1027-1043.

Pik, R., and B. Marty (2009). Helium isotopic signature of modern and fossil fluids associated with the Corinth rift fault zone (Greece): Implication for fault connectivity in the lower crust, Chemical Geol., 266, 67-75.

Sachpazi, M., A. Hirn, C. Clément, F. Haslinger, M. Laigle, E. Kissling, P. Charvis, Y. Hello J.-C. Lépine, M. Sapin and J. Ansorge (2000). Western Hellenic subduction and Cephalonia Transform: local earthquakes and plate transport and strain, Tectonophysics, 319, 301-319.

Seher, T., and I.G. Main (2004). A statistical evaluation of a "stress-forecast" earthquake, Geophys. J. Int., 157, 187193.

Sibson, R.H. (1990). Rupture nucleation on unfavorably oriented faults, Bull. Seismol. Soc. Am., 80, 1580-1604.

Trauth, S.N. (2010). Matlab $₫$ Recipes for Earth Sciences, 3rd Edition, Springer-Verlag, Berlin/Heidelberg.

Underhill, J. (1989). Late Cenozoic deformation of the Hellenide foreland, western Greece, Geol. Soc. Am. Bull., 101, 613-634.

Wessel, P., and W.H.F. Smith (1998). New, improved version of the Generic Mapping Tools Released, EOS Trans. AGU, 79, 579.

Xypolias, P., and T. Doutsos (2000). Kinematics of rock flow in a crustal scale shear zone: implication for the orogenic evolution of the SW Hellenides, Geol. Mag., 137, 81-96.

Zatsepin, S.V., and S. Crampin (1997). Modelling the compliance of crustal rock-I. Response of shear-wave splitting to differential stress, Geophys. J. Int., 129, 477-494.

\footnotetext{
${ }^{\star}$ Corresponding author: Efthimios Sokos,

University of Patras, Seismological Laboratory, Patras, Greece; email: esokos@upatras.gr.
}

(C) 2012 by the Istituto Nazionale di Geofisica e Vulcanologia. All rights reserved. 


\section{Appendix A}

F statistic test for directional data

Let us consider: $\theta_{1}, \theta_{2}, \ldots, \theta_{n}$ and $\varphi_{1}, \varphi_{2}, \ldots, \varphi_{m}$ as the two sets of azimuth measurements. We wish to statistically test the hypothesis that they belong to the same distribution. Before using the appropriate statistic, a specific analysis relative to the directional data has to be followed [Trauth 2010]. The characteristics of the directional data are described by measures of central tendency and dispersion, which are similar to the statistical characterization of univariate datasets. Initially, we need to calculate the resultant or mean direction for the sets of angular data according to the relationships:

$$
\begin{aligned}
& x_{1 r}=\sum \sin \theta_{1} \\
& y_{1 r}=\sum \cos \theta_{1}
\end{aligned} \text { and } \quad \begin{aligned}
& x_{2 r}=\sum \sin \phi_{1} \\
& y_{2 r}=\sum \cos \phi_{1}
\end{aligned}
$$

The resultant directions of the data are given by:

$$
\bar{\theta}=\tan ^{-1}\left(x_{1 r} / y_{1 r}\right) \text { and } \bar{\phi}=\tan ^{-1}\left(x_{2 r} / y_{2 r}\right)
$$

and the mean resultant lengths are:

$R_{1}=\frac{1}{n} \sqrt{\left(x_{1 r}^{2}+y_{1 r}^{2}\right)}$ and $R_{2}=\frac{1}{m} \sqrt{\left(x_{2 r}^{2}+y_{2 r}^{2}\right)}$ respectively.

The test statistic that we used for testing the similarity between the two mean directions is the F-statistic, and it is given by the relationship:

$$
F=\left(1+\frac{3}{8 k}\right) \frac{(N-2)\left(R_{1}+R_{2}-R_{\text {all }}\right)}{N-R_{1}-R_{2}}
$$

where $k$ is the concentration parameter, which can be obtained from tables using $R_{\text {all }}, R_{1}$ and $R_{2}$ are the mean directions (resultants) of the two datasets, respectively, and $R_{\text {all }}$ is the resultant of the combined datasets. The calculated F-statistic is compared with the critical values from the standard $F$ tables, and the two mean directions are not significantly different if the measured $F$ is lower than the critical $F_{c r}$. Applying the aforementioned statistical test to our data with a level of significance $5 \%$, we estimate $F=0.85$ and $F_{c r}=1.44$. As $F<F_{c r}$, we conclude that there is no statistical evidence that supports the rejection of the null hypothesis, and therefore the two samples of data have been drawn from populations with the same mean direction.

\section{Appendix B}

Two-sample Kolmogorov-Smirnov test

In the geosciences, there are a lot of occasions where we want to test the hypothesis that two datasets derive from the same statistical distribution. However, the kind and sizes of the samples do not allow any assumption about their distribution (e.g., Gaussian distributed). In these cases, we need a nonparametric two-sample statistical test for checking this hypothesis. Such a test is the two-sample Kolmogorov-Smirnov (KS) test [Gibbons 1971]. The two-sample KS test is one of the most used and general nonparametric method for comparing two populations, as it is sensitive to differences in both the location and shape of the empirical cumulative distribution functions of the two samples. Specifically, let us assume $X_{1}, X_{2}$, two datasets, of length $\mathrm{n}$ and $\mathrm{m}$, respectively, and let $F_{1, n}(x), F_{2, m}(x)$ be their empirical distributions. We need to test under what circumstances the hypothesis $F_{1, n}(x)=F_{2, m}(x)$ (the null hypothesis) is valid. In this case, the KS statistic is:

$$
D_{n, m}=\sup _{x}\left|F_{1, n}(x)-F_{2, m}(x)\right|
$$

and the null hypothesis is rejected, with a level of significance $\alpha$ if:

$$
q=\sqrt{\frac{n m}{n+m}} D_{n, m}>K_{a}
$$

where $K_{\alpha}$ is a constant threshold value that is derived from the Kolmogorov distribution. Applying this hypothesis-testing procedure in our phase delay data, with a significance level $\alpha=5 \%$, the values of $q$ and $K_{\alpha}$ are 0.41 and 0.05 , respectively. Since $q>K_{\alpha}$, we can conclude that the null hypothesis has to be rejected; i.e., the two datasets have not been drawn from the same distribution. 